Research Paper

\title{
Risk-taking Behavior Under the Effect of Emotional Stimuli Among Children and Adults
}

\author{
Fatemeh Shahrabi Farahani $^{1}$ (D), Reza Khosrowabadi ${ }^{1}$ (D), Gholamreza Jaafari ${ }^{2^{*}}$ (iD)
}

1. Institute for Cognitive \& Brain Sciences, Shahid Beheshti University, Tehran, Iran.

2. Center for Complex Networks \& Social Data Science, Faculty of Physics, Shahid Beheshti University, Tehran, Iran.

\begin{tabular}{l|l}
$\begin{array}{c}\text { Use your devicto san and } \\
\text { read the article online }\end{array}$ & $\begin{array}{l}\text { Citation Shahrabi Farahani, F., Khosrowabadi, R., Jaafari, G. R. Risk-taking Behavior Under the Effect of Emo- } \\
\text { tional Stimuli Among Children and Adults. Basic and Clinical Neuroscience, 13(4), 585-594. http://dx.doi.org/10.32598/ } \\
\text { bcn.2021.2508.1 }\end{array}$ \\
doi http://dx.doi.org/10.32598/bcn.2021.2508.1
\end{tabular}

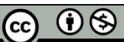

Article info:

Received: 19 Apr 2019

First Revision: 10 Aug 2020

Accepted: 11 Oct 2020

Available Online: $01 \mathrm{Jul} 2022$

Keywords:

Risk-taking behavior, Emotional priming, Dual system theory, Development

\section{AB S T RAC T}

Introduction: Risk-taking has an important role in human life, either positive or negative. Finding a method to control or drive this in a particular way can affect the health of individuals and communities by discouraging negative risks, such as reckless driving, or encouraging positive risks. It has been shown that emotion induction can enhance risk-taking behavior. Nonetheless, studies are mainly conducted on adults and a gap to focus on adolescents group as the peak age of risk-taking is required. Therefore, a new risk-taking task is introduced and development of risk-taking behavior in children is compared with a group male adults. In addition, influence of positive and negative emotional images on the risk-taking behavior is also evaluated.

Methods: A total of 21 children and 20 adults participated in this experiment. Their risk taking behavior is obtained using a new version of the dice game task with emotional stimuli. Subsequently, performances of two groups before and after emotional priming are statistically compared.

Results: The results showed that children have a higher tendency to choose riskier options when they are affected by positive emotion, while adults are more risk-averse after being primed by negative emotion.

Conclusion: These findings can be helpful for policymakers and tutoring planners to control risk-taking behavior at different ages using the priming effect of positive and negative emotions.

\footnotetext{
* Corresponding Author:

Gholamreza Jafari

Address: Center for Complex Networks \& Social Data Science, Faculty of Physics, Shahid Beheshti University, Tehran, Iran.

Tel: +98 (21) 29902773

E-mail: gjafari@gmail.com
} 


\section{Highlights}

- Children perform riskier than adults in our new version of the game of dice task.

- Children are affected by choosing riskier options by positive priming.

- Adults are affected by choosing less risky options by negative priming.

- Results were proved by dual-process theory.

\section{Plain Language Summary}

Every second of our life is consistent with decision-making. When you decide you face conditions that you do not know the result when you choose them. Choosing these options is associated with risks. Choosing these options can have both advantages and disadvantages. Therefore, it will be very useful for communities, if they can find a way to control it. In this study, we aimed to test whether it is possible to control risk-taking by viewing emotional pictures before decision-making or not. Hence, we design gambling-like experiments and test adults and children using this experiment. These two age groups were used to test the existence of any difference or similarity between their behaviors. We used three main emotions to check their effect on people's choices. We wanted to check what happens to people's decisions if they are faced with positive, negative, or neutral images before their choice. Results showed that children were riskier than adults and affected more when facing positive images and selecting riskier options. On the other hand, adults are more affected by negative images and chose safer options after seeing the pictures in this emotion.

\section{Introduction}

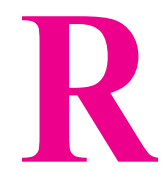

isk-taking is defined as a behavior that may result in a positive outcome (e.g., financial reward, pleasant physical or psychological sensations) and also carries some probabilities of a negative outcome (e.g., injury, financial loss) (Lejuez et al., 2002; MacPherson et al., 2010). Experimental evidence exists in distinctions between risk-taking of different age groups (Cauffman et al., 2010; Duell et al., 2018; Levin, Weller, Pederson, \& Harshman, 2007; Levin, Bossard, Gaeth, \& Yan, 2014). These differences are explained as interactions between cognitive processes, neurodevelopmental changes, and experience (Duell et al., 2018; Mitchell, Schoel, \& Stevens, 2008). This developmental behavior follows an inverted-U shape across age groups with greater risk-taking among adolescents due to variation in the relationship between cognitive control and reward processing systems (Duell et al., 2018; Somerville, Hare, \& Casey, 2011; Willoughby, Good, Adachi, Hamza, \& Tavernier, 2013). This relationship between these two developmental systems leads to differences in the vulnerability of risk-taking (Willoughby et al., 2013). Research confirms that risk-taking behavior can be affected by emotions (Kozlowski, Hutchinson, Hurley, Rowley, \& Sutherland, 2017; Vinckier, Rigoux, Oudiette, \& Pessiglione, 2018). Previous research on young adults showed that positive affect leads to lower risk perceptions than neutral (Haase \& Silbereisen, 2011).

The debate about the effect of the type of emotional category on risky behavior continues. For instance, Grable and his colleagues (Grable \& Roszkowski, 2008) showed that adults in a positive (happy) mood have higher levels of financial risk tolerance, while Stanton et al. (Stanton Reeck, Huettel, \& LaBar, 2014) reported that a positive (happy) mood induction increased riskseeking behavior compared to neutral mood, whereas a sad mood induction procedure did not induce behavioral differences compared to neutral mood. These moods are internally induced tempers. Other studies have linked positive mood or emotional states to reduced risk-taking (Isen, 1987; Isen, Nygren, \& Ashby, 1988; Loewenstein, Weber, Hsee, \& Welch, 2001). No consensus exists in the scientific literature regarding the effects of negative emotions on risk-taking. While some papers documented the fact that experimentally induced negative emotions, as well as anxious and depressive states, lead to more risk-averse preferences (Heilman, Crişan, Houser, Miclea, \& Miu, 2010; Kusev et al., 2017), other authors provide empirical evidence supporting a positive relationship between negative emotions and risk-seeking (Mittal \& Ross Jr, 1998). 
According to the appraisal tendency hypothesis (Lerner \& Keltner, 2000; Smith \& Ellsworth, 1985), each emotion is associated with a specific appraisal dimension (certainty, pleasantness, attentional activity, control, anticipated effort, and responsibility (Smith \& Ellsworth, 1985), which, in turn, determines the influence of specific emotions on judgments and decisions. For instance, induced fear was associated with pessimistic judgments of future events and risk-averse choices, whereas induced anger was associated with more optimistic judgments and a more risk-seeking behavioral pattern (Han, Lerner, \& Keltner, 2007). Happiness, although positively valenced, is associated with an elevated sense of certainty and individual control (Han et al., 2007). Patterns of appraisals along these dimensions provide a basis for comparing and contrasting discrete emotions. Because adolescence is associated with riskier activities, much attention has been paid on risk-taking behaviors of this age group (Figner \& Weber, 2011; Steinberg, 2007, 2010), while little research has been conducted to study the behavior of children and adults (Steinberg, 2008). Behavioral data regarding emotional influences on risk-taking are also less consistent and most of them were conducted only for adults. In this study, risk-taking behavior is examined under the effect of emotional stimuli in two opposite ranges of valence to clarify emotions' effect on two less examined age groups (children vs adults). It is hypothesized that due to a lack of maturation in children's brains (Defoe, Dubas, Figner, \& van Aken, 2015; Levin \& Hart, 2003; Romer, Reyna, \& Satterthwaite, 2017) they engage more in risky behaviors than adults. It is also proposed that positive emotions lead to greater risk-seeking because people are more optimistic about future outcomes when they feel good. Similarly, negative emotions, such as anxiety, make individuals more pessimistic about future outcomes, and this can lead to risk aversion (Johnson \& Tversky, 1983). This study is designed to address mentioned shortage in the existing literature. To do this, the effect of three conditions of two positive and negative emotional stimuli and one neutral condition were investigated in a within-subject design on two age groups of adults and children. Therefore, positive emotions are expected to encourages riskier behaviors, while negative emotion have the opposite effect on children and adults.

\section{Materials and Methods}

\section{Emotional stimuli}

The effects of these two categories of the international affective picture system (IAPS) (Lang, Bradley, \& Cuthbert, 2008) on risk-taking behavior were investigated in this paper. These categories included 50 pictures with different valence rates (Appendix 1 lists their IAPS numbers). They were used as emotional stimuli in a modified version of the game of dice task (Brand et al., 2005). The norms which were used in this experiment were provided by Libkuman (Libkuman, Otani, Kern, Viger, \& Novak, 2007). Table 1 presents the mean and standard deviation of these images. They were mainly categorized as positive (happy) and negative (fear) emotions. Valence refers to how pleasant or unpleasant a stimulus is. Arousal refers to levels of activation reflected in physiological responses, such as skin conductance, heart rate, and the startle response. Specific emotions can be placed on this two-dimensional space. For example, happiness is moderately arousing with positive valence, excitement is highly arousing with positive valence, sadness is moderately arousing with negative valence, and anger is highly arousing with negative valence.

\section{Task}

The original type of this game (Game of Dice Task [GDT]) was developed by Brand and his colleagues in 2005 to measure decision-making impairments in korsakoff patients (Brand et al., 2005). The goal in the original GDT was to maximize the fictitious score in 18 throws of a single virtual die. Subjects had to guess one number of the die ( 1 to 6 ) that they thought was more probable to be thrown. They can choose one certain number or a combination of two, three, or four numbers. In this task, each alternative was associated with a determined amount of money depending on the winning probability, 1000 gain/ loss for the choice of a single number, 500 gain/loss for two numbers, 200 gain/loss for three numbers, and 100 gain/loss for four numbers. Participants won mentioned amount of money if their guess was true (the number they chose was thrown) and lost the same amount of money on the other hand. The related gain/loss was 500 while choosing two numbers, such as the numbers " 3 " and " 4 ". In this case, participants won 500 if either the number " 3 " or the number " 4 " was thrown, and they lost 500 if one of the other numbers occurred (the $1,2,5$, or $6)$. The same principle was applied to the combinations of three and four numbers (Brand et al., 2005).

The reason for producing a new task is to change the game design and make it easier for understanding, especially for children. The first challenge to doing this is to have groups of options with equal distribution over the screen. This was solved by putting each group of dice in a diagonal symmetricity on the screen. It changes the number of available options in each group. Another change is the number of trials. It 
Table 1. Mean $\pm S D$ of the the values for valence and arousal of the average pictures used for emotional groups

\begin{tabular}{cccc}
\hline \multicolumn{2}{c}{ Mean \pm SD } \\
\hline Happy Valence & Happy Arousal & Fear Valence & Fear Arousal \\
\hline $31.12 \pm 9.6$ & $1.74 \pm 0.29$ & $32.28 \pm 12.05$ & $1.48 \pm 0.45$ \\
\hline & & & NEUR SCIENCE
\end{tabular}

is hard for people to understand the task at first trials, thus it is better to have more trials than the original one. It is also enhancing the reliability of the overall results. Therefore, we increased the number of trials from 18 in the original experiment to 50 in the current version. This gave the ability to follow the process of decision-making in a symmetric design. A shorter distance from the center of the screen represented a riskier option, whereas a greater distance represented a safer choice. The expected value for the single dice is $(1000 \times 1.6)-(1000 \times 5.6)=-666.6667$, for two numbers dice is $(500 \times 2.6)-(500 \times 4.6)=-166.67$, for three numbers dice is $(200 \times 3.6)-(200 \times 3.6)=0$ and for four numbers dice is $(100 \times 4.6)-(100 \times 2.6)=33.33$. These are the same as the original task. Choosing any options results in a positive value when they guess true or a negative value when they guess false.

\section{Emotional task}

Another addition to the original GDT is emotional stimuli. Because this game assessed the influence of emotional pictures on decision-making. In each trial, before any selection, one emotional image was displayed on the screen. These pictures were selected from positive and negative sets of IAPS as mentioned earlier. For the control group, a uniform gray colored rectangle with the rgb code $(128,128,128)$ was used as neutral stimuli. Participants were treated with all emotional stimuli with different between-group and similar within-group sequences. The task starts when partici-

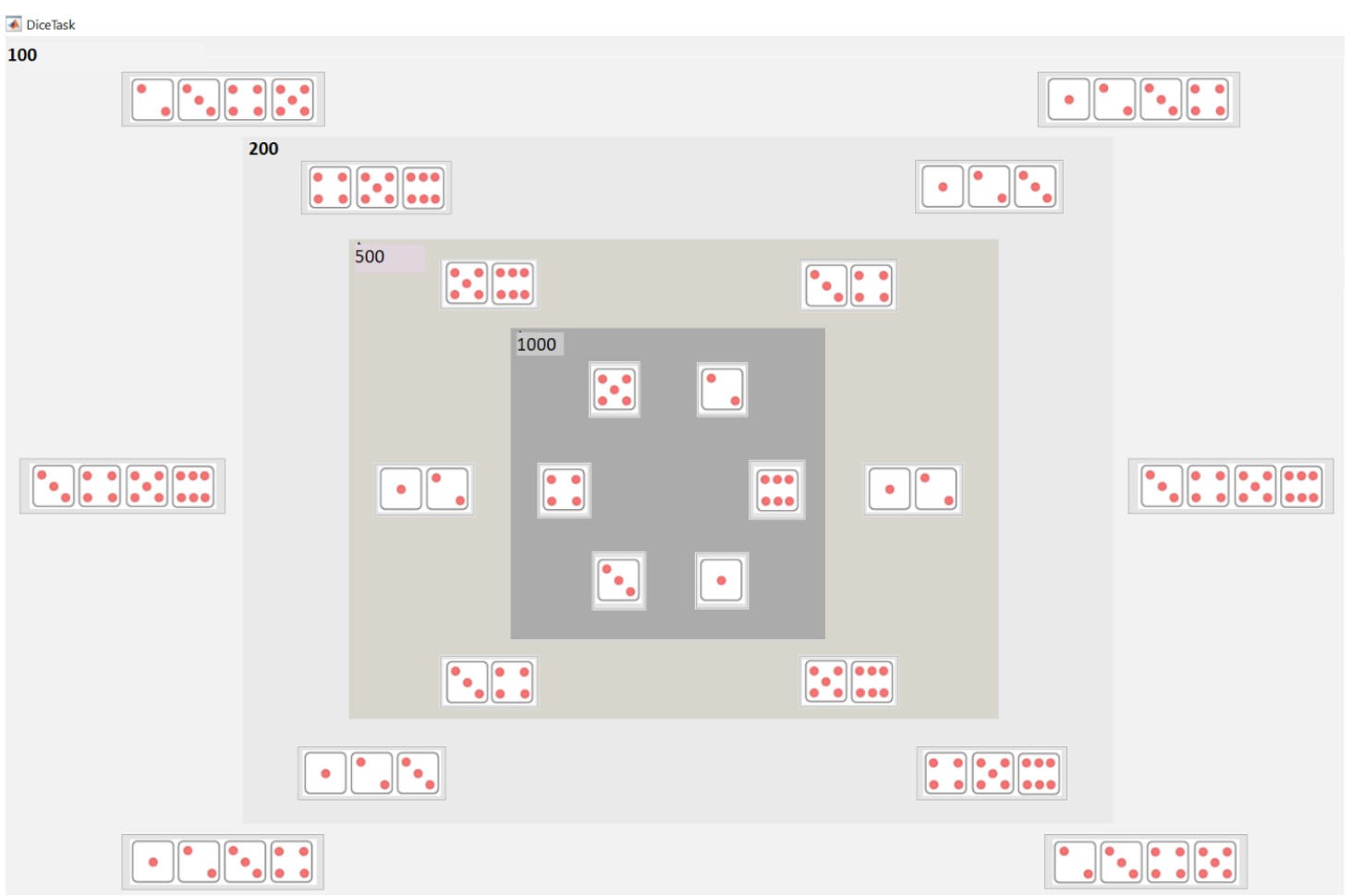

Figure 1. A screen shot of the game

Screen-shot of the task, this picture has four dice groups. Group one, which contains 6 separate dice, group two, which has 6 two dice options, group three which has 4 three options, and group four, which has 6 four options. One dice group pays 1000, two dice group pays 500, the third dice group pays 200 and the fourth dice group pays 100 . This is what a participant faces when doing the task. He/she should select one of these options for each round. 


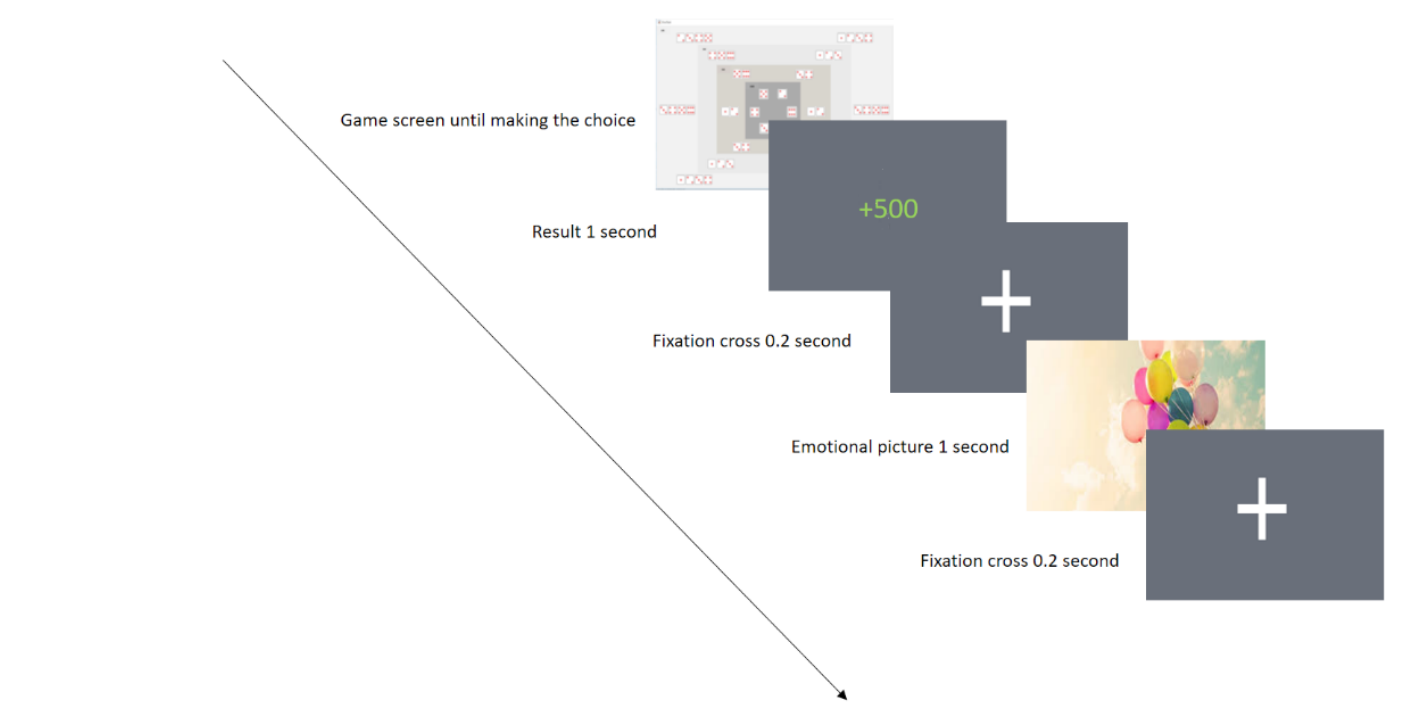

Figure 2. Task process

NEUR SCIENCE

Process of the experiment. This figure depicts what happens in one trial of the experiment. First, participants see the dice option screen. It appears until someone chooses one option. Then the result of the choice is displayed on the screen for $1 \mathrm{~s}$. If the choice was correct, it is green with a positive sign and adds to the overall outcome, but if it was wrong, it is red with the negative sign and subtracts from the overall outcome. Following this part, a fixation cross is shown for $0.2 \mathrm{~s}$. Then, depending on the emotional treatment of the current group (positive, negative, or neutral), one of the prerecorded IAPS pictures appeared on the screen for $1 \mathrm{~s}$. This is emotional priming that is supposed to affect the next round's choice. Again a fixation cross is displayed on the screen, ending a round and preparing participants for the next round.

pants see Figure 1. It allows them to make their choice by selecting their guesses from the game screen. The result of the throws was previously randomized and saved and is the same for everyone to control the effect of win/loss over the next choice.

The game process was as follows as shown in Figure 2. They start the game with an initial balance of 10000 points. First, they selected their choice from the screen. Then the result of their choice appeared on the screen for one second. If their guess was true, a green number with a positive sign was shown on the screen. This number was added to their total score as a reward. However, on the other hand, if their guess was wrong, it was shown in red color with a minus sign. This value decreased from their total score as a punishment. Following this part, a fixation cross appeared on the screen for $0.2 \mathrm{~s}$ to move participants' attention to the center of the screen. According to those treatments in which they had been participating in it -positive, negative, or neutral- one emotional image was displayed for $1 \mathrm{~s}$, followed by another fixation point for $0.2 \mathrm{~s}$, with a mouse pointer centered. This procedure was repeated for each person 50 times in the positive group, 50 times in the negative group, and 50 times in the neutral group. One number dice are riskier and four number dice are safer choices.
These selected options and their reaction times were saved for further analysis.

\section{Participants}

A total of 21 children aged (9-11 years) from four classes of a Karimeh Ahlebait primary school in Tehran City, Iran and 10 adults from the Physics Department of Shahid Beheshti University, and 10 adults from Arianpardaz company aged (25-28 years) were randomly selected and enrolled in the study. They were all students. They conducted the study in a within-subject design. Each person played the game in all conditions of positive, negative, and neutral emotional images. The study took place in Tehran City, Iran. A detailed study protocol that explained the study goal and methodology was approved by the institutional review board. Participants received an information sheet assuring them that the data obtained would be handled confidentially and anonymously, and they were asked to give written informed consent. Parents were required to provide consent on behalf of their children. All parents gave permission.

\section{Procedure}

Participants were tested independently in a quiet room with a laptop with a $1920 \times 1080$ screen resolution. In the beginning, the experimenter gave participants a consent statement to read over. In addition, the experimenter 
reviewed the instructions with the participants and answered any questions. Participants were tested randomly in three separate sessions, which were considered positive, negative, and neutral emotional conditions. They did not know the reason for showing pictures. They were told that they need to choose one of the options on the screen to enhance their overall points.

\section{Analysis}

To analyze the effects of emotional treatments on the risk-taking of children and adults, their choices (as a dependent variable) were classified based on selected numbers. Here choosing one option dice gets 1, two option dice get 2 , three option dice get 3 , and four option dice get 4 . The time of the selection of options is also recorded as their reaction time to compare between groups. Based on Hardy et al (Hardy, Hinkin, Levine, Castellon, \& Lam, 2006) who classified dice groups with one or two numbers as risky or disadvantageous, while with three and four numbers as non-risky or advantageous, the participant's overall index of performance, defined as an index of risk-taking behavior is calculated from the number of options chosen from a "risky" group (two and one dice groups) minus the number of choices from a "safe" group (i.e., from three and four dice groups). Thus, higher scores indicate riskier task performance while lower scores indicate more optimal performance (i.e., winnings will be greater).

All statistical analyses were carried out with MATLAB. Here, analysis of variance (ANOVA) and t test were used to determine whether a significant difference was observed between the values of age groups $\times$ emotional priming in reaction-time and risk-taking or not. Since the task was run for 50 trials, each person has 50 values for each emotional treatment. Thus each person had 150 values, 50 for positive priming, 50 for negative priming, and 50 for neutral priming. For each of these 50 rounds, the total of the risky and non-risky choices, mean reaction time, and Hardy's index were calculated. These values were calculated for every person for all 50 rounds. Thus each person has six values. Reaction time and Hardy's index for positive, negative, and neutral conditions. Since we run the experiment over two groups of children and adults, we also had 2 age groups. Therefore, six groups existed in total (children affected by positive emotions, adults affected by positive emotions children affected by negative emotions, adults affected by negative emotions, children affected by neutral emotions, adults affected by neutral emotions). To answer the research question of whether emotional stimuli can affect risk-taking or whether they affect different age groups differently, a 1-way analysis of variance (ANOVA) was used. If a significant group difference was observed, then a follow-up t test analysis was conducted to examine the hypotheses.

\section{Results}

Using the $\mathrm{t}$ test on the Hardy's risk-taking index (Hardy et al., 2006) shows a significant difference between the two age groups while children are riskier than adults $(\mathrm{P}=0.0181)$. However, no significant effect is observed on emotional priming. Comparing emotional groups and age groups based on reaction time shows that no significant effect is observed between emotional stimuli and reaction time as well as age and reaction time. Therefore, emotional stimuli have no different effect on children and adults' reaction times in our experiment. As a result of observing the age difference between all groups, the next step is to find significant groups. Thus, the comparisons conducted are between adults and children in positive, negative, and neutral emotions separately while a significant difference is observed in positive emotion $(\mathrm{P}=0.0094)$ and children perform riskier than adults.

Rational decision-makers decide based on expected value, thus they look for options with higher expected outcomes. However, in this study, there is just one class of options with a positive expected value, which is classified as a rational, four-number dice group. However, in the whole experiment, participants made only $35.8 \%$ of their choices on this option. By looking at the number of times that rational option was chosen by each age group considering emotional priming, no significant difference exists that indicates the effect of emotion on rational choice. This difference manifests itself considerably regardless of priming in both the children and adults group, meaning that adults made more rational decisions overall $(\mathrm{P}=0.0346)$. Post-hoc comparison of this part shows a significant difference between adults and children in negative emotion $(\mathrm{P}=0.0450)$ while adults chose rational options more than children. However, this includes only $40.06 \%$ of adults' choices, indicating that they did not decide rationally.

\section{Discussion}

As hypothesized, in this study, children performed riskier compared to adults, especially in positive emotions. These findings are compatible with longitudinal and brain studies of risk-taking behavior (Harden \& TuckerDrob, 2011; Willoughby et al., 2013). According to dualprocess decision-making models, an intuitive, automatic system exists, which is often reliant on affect, reward, 
and current emotions for making decisions ("system 1 "), versus a controlled, and reflective system ("system 2") (Harden \& Tucker-Drob, 2011; Willoughby et al., 2013). System 1 appears from birth while the sensitivity of system 2 increases later (Harden \& Tucker-Drob, 2011; Willoughby et al., 2013). Relation between these two developmental systems leads to the difference in the vulnerability of risk-taking (Willoughby et al., 2013)). Therefore, it is concluded that children perform riskier than adults due to their higher amount of reward-seeking compared to their immature cognitive control. This is also brain regions responsible for reward processing and those necessary for cognitive control that varies dynamically across development (Duell et al., 2018; Somerville et al., 2011). Therefore, the task introduced in this paper can properly measure risk-taking behavior.

\section{Conclusion}

Among different affective groups, children's responses are affected by positive emotions (happiness) towards riskier choices. While negative emotion (fear) has a significant effect on adults. It results in less riskseeking compared to other groups. Inhibitory control, which is a part of system 2, operates according to formal rules of logic and can block affective impulses. It actively works for adults but not for children. Positive impulses enhance risky behavior by optimizing the outcome of the decision and reinforcing the risky behavior. However, in adults, a stronger control system prevents further risk. However, this system does not work like this in children and reinforces risk-taking among them. On the other hand, negative impulses cause pessimism about the outcome of the decision and reinforce the nonrisky behavior that enters the control system as a further warning alarm. Therefore, it puts adults at greater riskaversion than children who do not yet benefit from this mature system. The current study was performed only on 41 people in two age groups, children and adults. In addition to increasing the number of samples to improve experimental power, it is recommended to add the adolescent group, which helps us to observe developmental changes in this experimental condition.

\section{Ethical Considerations}

\section{Compliance with ethical guidelines}

All ethical principles are considered in this article. The participants were informed of the purpose of the research and its implementation stages. They were also assured about the confidentiality of their information and were free to leave the study whenever they wished, and if desired, the research results would be available to them. A written consent has been obtained from the subjects. principles of the Helsinki Convention were also observed.

\section{Funding}

This research did not receive any grant from funding agencies in the public, commercial, or non-profit sectors.

\section{Authors' contributions}

Conceptualization and Supervision: Reza Khosrowabadi, Gholamreza Jaafari; Methodology: Fatemeh Sahrabi Farahani, Reza Khosrowabadi; Investigation, Writing - original draft, and Writing - review \& editing: All authors; Data collection: Fatemeh Sahrabi Farahani; Data analysis: All Authors; Funding acquisition and Resources: All Authors.

\section{Conflict of interest}

The authors declared no conflict of interest.

\section{Acknowledgments}

We would like to express our gratitude to all participants that contributed in this study and our special thanks to the Institute for Cognitive and Brain Science at the Shahid Beheshti University for their technical support.

\section{References}

Brand, M., Fujiwara, E., Borsutzky, S., Kalbe, E., Kessler, J., \& Markowitsch, H. J. (2005). Decision-making deficits of korsakoff patients in a new gambling task with explicit rules: Associations with executive functions. Neuropsychology, 19(3), 267. [DOI:10.1037/0894-4105.19.3.267] [PMID]

Cauffman, E., Shulman, E. P., Steinberg, L., Claus, E., Banich, M. T., Graham, S., et al. (2010). Age differences in affective decision making as indexed by performance on the Iowa Gambling Task. Developmental Psychology, 46(1), 193. [DOI:10.1037/a0016128] [PMID]

Defoe, I. N., Dubas, J. S., Figner, B., \& van Aken, M. A. (2015) A meta-analysis on age differences in risky decision making: Adolescents versus children and adults. Psychological Bulletin, 141(1), 48. [DOI:10.1037/a0038088] [PMID]

Duell, N., Steinberg, L., Icenogle, G., Chein, J., Chaudhary, N., Di Giunta, L., et al. (2018). Age patterns in risk taking across the world. Journal of Youth and Adolescence, 47(5), 1052-1072. [DOI:10.1007/s10964-017-0752-y] [PMID] [PMCID] 
Figner, B., \& Weber, E. U. (2011). Who takes risks when and why? Determinants of risk taking. Current Directions in Psychological Science, 20(4), 211-216. [DOI:10.1177/0963721411415790]

Grable, J. E., \& Roszkowski, M. J. (2008). The influence of mood on the willingness to take financial risks. Journal of Risk Research, 11(7), 905-923. [DOI:10.1080/13669870802090390]

Haase, C. M., \& Silbereisen, R. K. (2011). Effects of positive affect on risk perceptions in adolescence and young adulthood. Journal of Adolescence, 34(1), 29-37. [DOI:10.1016/j. adolescence.2010.03.004] [PMID]

Han, S., Lerner, J. S., \& Keltner, D. (2007). Feelings and consumer decision making: The appraisal-tendency framework. Journal of Consumer Psychology, 17(3), 158-168. [DOI:10.1016/S1057-7408(07)70023-2]

Harden, K. P., \& Tucker-Drob, E. M. (2011). Individual differences in the development of sensation seeking and impulsivity during adolescence: Further evidence for a dual systems model. Developmental Psychology, 47(3), 739. [DOI:10.1037/a0023279] [PMID]

Hardy, D. J., Hinkin, C. H., Levine, A. J., Castellon, S. A., \& Lam, M. N. (2006). Risky decision making assessed with the gambling task in adults with HIV. Neuropsychology, 20(3), 355. [DOI:10.1037/0894-4105.20.3.355] [PMID] [PMCID]

Heilman, R. M., Crişan, L. G., Houser, D., Miclea, M., \& Miu, A. C. (2010). Emotion regulation and decision making under risk and uncertainty. Emotion, 10(2), 257. [DOI:10.1037/ a0018489] [PMID]

Isen, A. M. (1987). Positive affect, cognitive processes, and social behavior. In Advances in experimental social psychology (Vol. 20, pp. 203-253). Elsevier. [DOI:10.1016/S0065-2601(08)60415-3]

Isen, A. M., Nygren, T. E., \& Ashby, F. G. (1988). Influence of positive affect on the subjective utility of gains and losses: It is just not worth the risk. Journal of Personality and Social Psychology, 55(5), 710. [DOI:10.1037/0022-3514.55.5.710] [PMID]

Johnson, E. J., \& Tversky, A. (1983). Affect, generalization, and the perception of risk. Journal of Personality and Social Psychology, 45(1), 20. [DOI:10.1037/0022-3514.45.1.20]

Kozlowski, D., Hutchinson, M., Hurley, J., Rowley, J., \& Sutherland, J. (2017). The role of emotion in clinical decision making: An integrative literature review. BMC Medical Education, 17(1), 255. [DOI:10.1186/s12909-017-1089-7] [PMID] [PMCID]

Kusev, P., Purser, H., Heilman, R., Cooke, A. J., Van Schaik, P., Baranova, V., Martin, R., \& Ayton, P. (2017). Understanding risky behavior: The influence of cognitive, emotional and hormonal factors on decision-making under risk. Frontiers in Psychology, 8, 102 [DOI:10.3389/fpsyg.2017.00102] [PMID] [PMCID]

Lang, P. J., Bradley, M. M., \& Cuthbert, B. N. (2008). International affective picture system (IAPS): Affective ratings of pictures and instruction manual. University of Florida, Gainesville. Tech Rep A-8.

Lejuez, C. W., Read, J. P., Kahler, C. W., Richards, J. B., Ramsey, S. E., Stuart, G. L., Strong, D. R., \& Brown, R. A. (2002) Evaluation of a behavioral measure of risk taking: The Balloon Analogue Risk Task (BART). Journal of Experimental Psychology: Applied, 8(2), 75. [DOI:10.1037/1076-898X.8.2.75] [PMID]
Lerner, J. S., \& Keltner, D. (2000). Beyond valence: Toward a model of emotion-specific influences on judgement and choice. Cognition \& Emotion, 14(4), 473-493. [DOI:10.1080/026999300402763]

Levin, I. P., Bossard, E. A., Gaeth, G. J., \& Yan, H. (2014). The combined role of task, child's age and individual differences in understanding decision processes. Judgment and Decision Making, 9(3), 274

Levin, I. P., \& Hart, S. S. (2003). Risk preferences in young children: Early evidence of individual differences in reaction to potential gains and losses. Journal of Behavioral Decision Making, 16(5), 397-413. [DOI:10.1002/bdm.453]

Levin, I., Weller, J., Pederson, A., \& Harshman, L. (2007). Agerelated differences in adaptive decision making: Sensitivity to expected value in risky choice.

Libkuman, T. M., Otani, H., Kern, R., Viger, S. G., \& Novak, N. (2007). Multidimensional normative ratings for the international affective picture system. Behavior Research Methods, 39(2), 326-334. [DOI:10.3758/BF03193164] [PMID]

Loewenstein, G. F., Weber, E. U., Hsee, C. K., \& Welch, N. (2001). Risk as feelings. Psychological Bulletin, 127(2), 267. [DOI:10.1037/0033-2909.127.2.267] [PMID]

MacPherson, L., Reynolds, E. K., Daughters, S. B., Wang, F., Cassidy, J., Mayes, L. C., \& Lejuez, C. (2010). Positive and negative reinforcement underlying risk behavior in early adolescents. Prevention Science, 11(3), 331-342. [DOI:10.1007/ s11121-010-0172-7] [PMID] [PMCID]

Mitchell, S. H., Schoel, C., \& Stevens, A. A. (2008). Mechanisms underlying heightened risk taking in adolescents as compared with adults. Psychonomic Bulletin \& Review, 15(2), 272-277. [DOI:10.3758/PBR.15.2.272] [PMID] [PMCID]

Mittal, V., \& Ross Jr, W. T. (1998). The impact of positive and negative affect and issue framing on issue interpretation and risk taking. Organizational Behavior and Human Decision Processes, 76(3), 298-324. [DOI:10.1006/obhd.1998.2808] [PMID]

Romer, D., Reyna, V. F., \& Satterthwaite, T. D. (2017). Beyond stereotypes of adolescent risk taking: Placing the adolescent brain in developmental context. Developmental Cognitive Neuroscience, 27, 19-34. [DOI:10.1016/j.dcn.2017.07.007] [PMID] [PMCID]

Smith, C. A., \& Ellsworth, P. C. (1985). Patterns of cognitive appraisal in emotion. Journal of Personality and Social Psychology, 48(4), 813. [DOI:10.1037/0022-3514.48.4.813] [PMID]

Somerville, L. H., Hare, T., \& Casey, B. (2011). Frontostriatal maturation predicts cognitive control failure to appetitive cues in adolescents. Journal of Cognitive Neuroscience, 23(9), 2123-2134. [DOI:10.1162/jocn.2010.21572] [PMID] [PMCID]

Stanton, S. J., Reeck, C., Huettel, S. A., \& LaBar, K. S. (2014). Effects of induced moods on economic choices. Judgment and Decision Making, 9(2), 167.

Steinberg, L. (2007). Risk taking in adolescence: New perspectives from brain and behavioral science. Current Directions in Psychological Science, 16(2), 55-59. [DOI:10.1111/j.14678721.2007.00475.x]

Steinberg, L. (2008). A social neuroscience perspective on adolescent risk-taking. Developmental Review, 28(1), 78-106. [DOI:10.1016/j.dr.2007.08.002] [PMID] [PMCID] 
Steinberg, L. (2010). A dual systems model of adolescent risktaking. Developmental Psychobiology: The Journal of the International Society for Developmental Psychobiology, 52(3), 216224. [DOI:10.1002/dev.20445] [PMID]

Vinckier, F., Rigoux, L., Oudiette, D., \& Pessiglione, M. (2018). Neuro-computational account of how mood fluctuations arise and affect decision making. Nature Communications, 9(1), 1708. [DOI:10.1038/s41467-018-03774-z] [PMID] [PMCID]

Willoughby, T., Good, M., Adachi, P. J., Hamza, C., \& Tavernier, R. (2013). Examining the link between adolescent brain development and risk taking from a social-developmental perspective. Brain and Cognition, 83(3), 315-323. [DOI:10.1016/j.bandc.2013.09.008] [PMID] 
Appendix

Appendix 1. IAPS numbers that are used in this study

No.

13001340130114401302146013031463193016021931161035001710597017215971172259721750 61901811620018126210192062131999623020406242205762432070625020916260215063002216 63122303631323106314231163502331637023416510234565402352655023606560251065702530 65712540682125506830265576402660848027919911460310225621104056281050576010515779 10525780107058001101583011135870112059101200598212015990122072821240732512748497 